This item was submitted to Loughborough's Research Repository by the author.

Items in Figshare are protected by copyright, with all rights reserved, unless otherwise indicated.

\title{
The influence of seat backrest angle on human performance during whole- body vibration
}

PLEASE CITE THE PUBLISHED VERSION

http://dx.doi.org/10.1080/00140139.2011.634030

PUBLISHER

(c) Taylor \& Francis Ltd.

VERSION

AM (Accepted Manuscript)

LICENCE

CC BY-NC-ND 4.0

\section{REPOSITORY RECORD}

Paddan, G.S., S.R. Holmes, Neil J. Mansfield, H. Hutchinson, C.I. Arrowsmith, S.K. King, R.J.M. Jones, and Andrew N. Rimell. 2019. "The Influence of Seat Backrest Angle on Human Performance During Whole-body Vibration”. figshare. https://hdl.handle.net/2134/12674. 
This item was submitted to Loughborough's Institutional Repository (https://dspace.lboro.ac.uk/) by the author and is made available under the following Creative Commons Licence conditions.

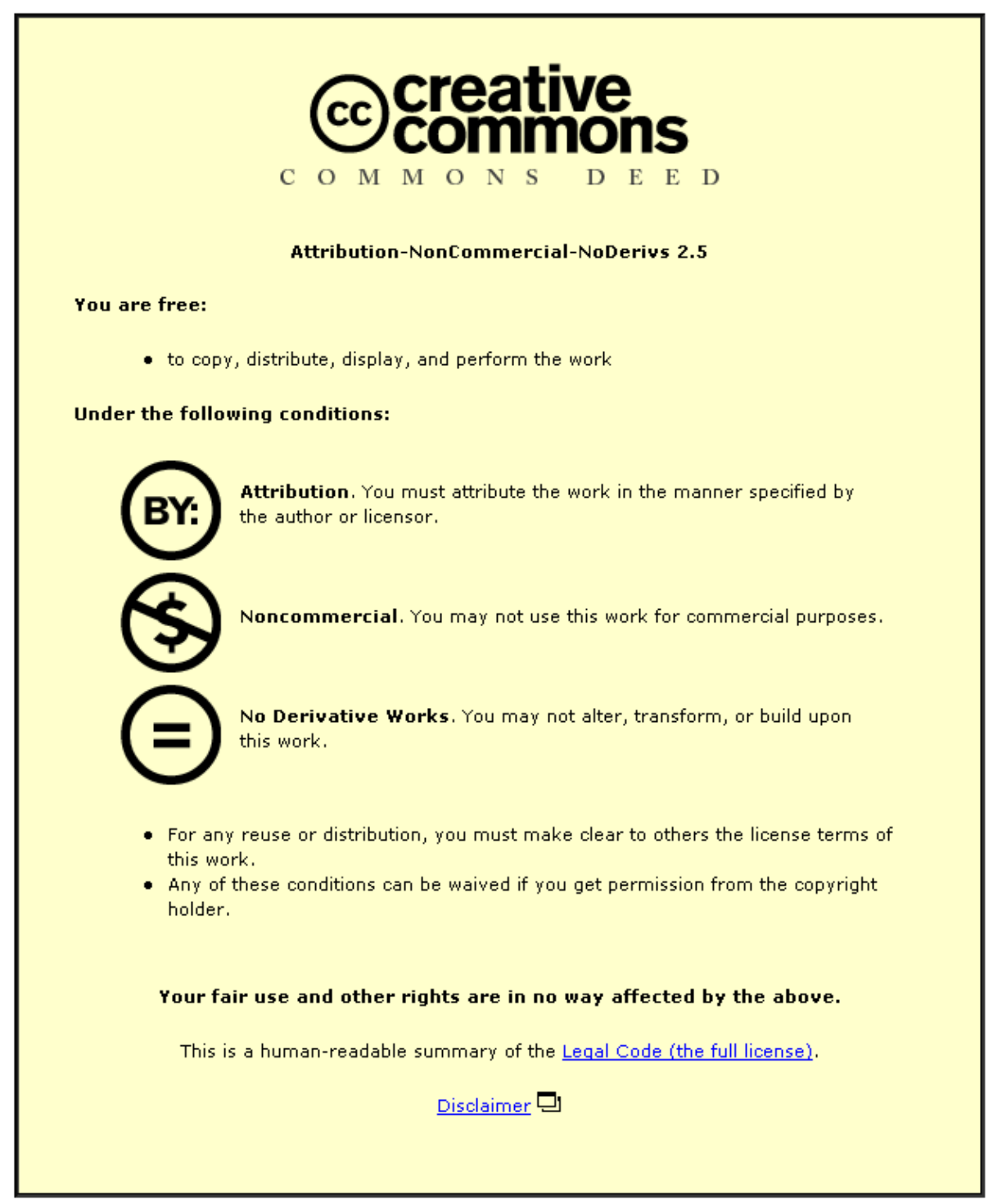

For the full text of this licence, please go to: http://creativecommons.org/licenses/by-nc-nd/2.5/ 


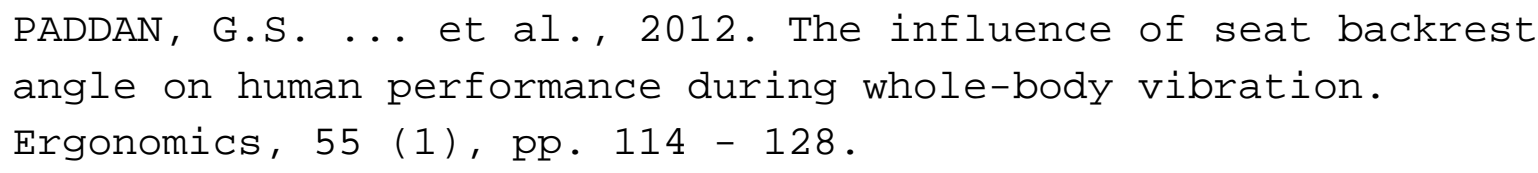

\begin{abstract}
This study investigated the effects of reclined backrest angles on cognitive and psychomotor tasks during exposure to vertical whole-body vibration. Twenty participants were each exposed to three test stimuli of vertical vibration: $2-8 \mathrm{~Hz} ; 8-14 \mathrm{~Hz}$ and 14$20 \mathrm{~Hz}$, plus a stationary control condition whilst seated on a vibration platform at five backrest angles: $0^{\circ}$ (recumbent, supine) to $90^{\circ}$ (upright). The vibration magnitude was $2.0 \mathrm{~ms}^{-2}$ root-mean-square. The participants were seated at one of the backrest angles and exposed to each of the three vibration stimuli while performing a tracking and choice reaction time tasks; then they completed the NASA-TLX workload scales. Apart from $22.5^{\circ}$ seat backrest angle for the tracking task, backrest angle did not adversely affect the performance during vibration. However, participants required increased effort to maintain performance during vibration relative to the stationary condition. These results suggest that undertaking tasks in an environment with vibration could increase workload and risk earlier onset of fatigue.
\end{abstract}

Practitioner Summary

Current vibration standards provide guidance for assessing exposures for seated, standing and recumbent positions, but not for semi-recumbent postures. This paper reports new experimental data systematically investigating the effect of backrest angle on human performance. It demonstrates how workload is elevated with whole-body vibration, without getting affected by backrest angle. 


\section{Introduction}

Whole-body vibration exposures that occur in transport environments show that the dominant motion is in the vertical direction, and that most of the vibration covers the frequency range $0.2-20 \mathrm{~Hz}$ (environments include passenger transport, earth-moving and industrial machinery, agricultural and forestry machines and military vehicles) (Mansfield 200514. Mansfield, N. J. 2005. Human response to vibration, Boca Raton, FL: CRC Press. ). The vertical biomechanical response of the human body shows a resonance at about 4-5 Hz, which coincides with the frequencies where people are most sensitive in psychophysical tests (BS 6841 1987). The exposure of the seated or standing persons to whole-body vibration, especially at frequencies in the human resonance range, can have various detrimental effects on perceived comfort, health and on performance (BS 6841 1987, ISO 2631-1 1997).

In terms of performance, whole-body vibration has been shown to have adverse effects on vision and hand-arm control (Griffin 19906. Griffin, M.J. 1990. Handbook of human vibration, London: Academic Press. ). The main functional degradation of vision occurs at vibration frequencies between 3 and $10 \mathrm{~Hz}$ where participants are looking at near visual targets, such as an instrument panel within a vehicle. If both the operator and the target (e.g. control panel) are undergoing vibration from the same source, it cannot be assumed that the motion of the eye and target are the same (Griffin 19906. Griffin, M.J. 1990. Handbook of human vibration, London: Academic Press. ). The nature of the biomechanical response of the human body means that at some frequencies the vibration experienced at the head can be greater than that at the seat (amplification), whereas at other frequencies, the vibration at the head can be less than that experienced at the seat (attenuation). This response is usually expressed in terms of the transmissibility (Griffin 19906. Griffin, M.J. 1990. Handbook of human vibration, London: Academic Press. , Mansfield 200514. Mansfield, N. J. 2005. Human response to vibration, Boca Raton, FL: CRC Press. ). For vertical vibration between 3 and $10 \mathrm{~Hz}$, there is an increase in the phase angle between vibration at the seat and at the head with increasing frequency (Griffin 19906. Griffin, M.J. 1990. Handbook of human vibration, London: Academic Press. ). In addition, vertical vibration applied to seated participants generates rotational motion of the head in the pitch axis, which reaches a peak at approximately $6 \mathrm{~Hz}$ (Paddan and Griffin 198820. Paddan, G. S. and Griffin, M. J. 1988. The transmission of translational seat vibration to the head. I. Vertical seat vibration. Journal of Biomechanics, 21: 191-197. ). Such head motion generates compensatory angular eye movements in opposite phase (i.e. the vestibuloocular reflex), which serves to stabilise a visual target at optical infinity. However, these compensatory reflex eye movements occur out of phase with the movement of the vehicle or platform and cannot be suppressed at frequencies above 1-2 Hz (Griffin 19906. Griffin, M.J. 1990. Handbook of human vibration, London: Academic Press. ). The combination of these factors produces blurring of the visual target (e.g. text presented on a visual display), resulting in increased difficulty in accurately perceiving the target data and an increase in the probability of errors in visual performance tasks (Griffin 19906. Griffin, M.J. 1990. Handbook of human vibration, London: Academic Press. ). 
As the frequency of vertical vibration increases above $15 \mathrm{~Hz}$, the vibration is further attenuated by the trunk before reaching the head (Paddan and Griffin 198820. Paddan, G. S. and Griffin, M. J. 1988. The transmission of translational seat vibration to the head. I. Vertical seat vibration. Journal of Biomechanics, 21: 191-197. ), resulting in a significant decrease in the detrimental effects on vision (Moseley et al. 198216. Moseley, M. J., Lewis, C. H. and Griffin, M. J. 1982. Sinusoidal and random whole-body vibration: comparative effects on visual performance. Aviation, Space and Environmental Medicine, 53: 1000-1005. ). The exception occurs if the vibration is extremely severe or is applied directly to the head. An increase in seat backrest angle towards the supine (recumbent) will result with the head being closer to the source of vertical vibration, thus increasing the transmission of vibration applied directly to the head. In the extreme, with the body in a supine posture, vibration in the 'vertical' direction will be in back-of-head to nose direction in such a posture, and frequency weighting Wj would be applicable when assessing vibration exposure at the head (ISO 2631-1 1997).

The ability to reach accurately for near controls and undertake tasks requiring fine manual dexterity is also adversely affected by whole-body vibration. Around 3-6 Hz, the resonance of the internal viscera (liver, intestine and gastric system) transmits through to the shoulder girdle, producing movement of the outstretched arm that is of higher amplitude and generally out of phase relative to the movement of the platform (Paddan 199318. Paddan, G. S. Hand movements during exposure to lateral seat vibration. UK Group Meeting on Human Response to Vibration, APRE, Farnborough. September1993. ). In addition, the biodynamic response of the body produces a hand resonance around 4-5 Hz (Griffin 19906. Griffin, M.J. 1990. Handbook of human vibration, London: Academic Press. , Paddan and Griffin 1995). The subjective discomfort experienced when reaching out at targets in a stationary environment has been assessed elsewhere (Wang and Trasbot 201126. Wang, X. and Trasbot, J. 2011. Effects of target location, stature and hand grip type on in-vehicle reach discomfort. Ergonomics, 54(5): 466-476. ).

The effect of whole-body vibration exposure on motor control is dependent on many factors. These include the task (e.g. entering data, pressing a button, joystick control), the vibration characteristics (frequency, direction, waveform and magnitude), the orientation and the dynamics of the control device and dynamic changes in operator characteristics (e.g. shifts in attention, assignment of priorities and strategies for coping with degraded hand control due to vibration). Although the effects of vibration on hand manipulation and control are difficult to predict, performance during exposure to vibration is generally impaired. For example, Corbridge and Griffin (19912. Corbridge, C. and Griffin, M. J. 1991. Effect of vertical vibration on passenger activities: writing and drinking. Ergonomics, 34(10): 1313-1332. ) exposed seated participants to vertical sinusoidal vibration and found that the greatest detriment in writing legibility occurred between 4 and $8 \mathrm{~Hz}$. Further details and models of hand-arm control error during whole-body vibration have been presented elsewhere (Lewis and Griffin 197811. Lewis, C. H. and Griffin, M. J. 1978. A review of the effects of vibration on visual acuity and continuous manual control. II: Continuous manual control. Journal of Sound and Vibration, 56(3): 415-457. , Jex and Magdaleno 19789. Jex, H. R. and Magdaleno, R. E. 1978. Biomechanical models for vibration feedthrough to hands and head for a semisupine pilot. Aviation, Space and Environmental Medicine, Section II, 
49: 304-316. , Jex and Magdaleno 1979, McLeod and Griffin 198915. McLeod, R. W. and Griffin, M. J. 1989. A review of the effects of whole-body translational vibration on continuous manual control performance. Journal of Sound and Vibration, 133: 55-115. ).

Yau et al. (201127. Yau, Y. J., Chao, C. J., Feng, W. Y. and Hwang, S. L. 2011. The effects of platform motion and target orientation on the performance of trackball manipulation. Ergonomics, 54(8): 745-754. ) showed that speed of response for a trackball-controlled screen-based task can be affected by low-frequency $(0.3 \mathrm{~Hz})$ vibration, but that error rates were not affected. Significant increases in subjective ratings of difficulty occurred for roll and pitch motions but not for vertical motion. The effect of higher frequencies of vibration was not reported.

Currently, two standards BS 6841 (1987) and ISO 2631-1 (1997) provide methodologies for the measurement and assessment of human response to whole-body vibration in terms of health, comfort, vision and manual control. The standards define frequency weightings for application to vibration at the seat, floor and backrest in the translational and rotational axes. For assessments of performance, the standards provide different methods of dealing with complex multi-axis vibration based on calculations of the root-mean-square (r.m.s.) of the frequency-weighted acceleration. Some of the frequency weightings provided allow the effect of whole-body vibration on visual and hand-arm performance to be predicted. However, both standards recommend the cautious use, and interpretation of these outputs as the effect of whole-body vibration on vision and manual hand-arm control is highly dependent upon the task and other factors discussed earlier. For example, there may be no adverse effect of whole-body vibration on visual performance if the size of text on a near display is sufficiently large (Griffin 19906. Griffin, M.J. 1990. Handbook of human vibration, London: Academic Press. ).

Paddan et al. (in press) investigated the effects of seating backrest angle on operator discomfort. This study was undertaken because current standards provide no strategy to take into account semi-recumbent postures such as those experienced by drivers of military vehicles, patients being transported by ambulance, some long-reach excavators used in demolition, race-car drivers and passenger transportation where seats recline to facilitate sleep (e.g. long-haul air travel, some trains, some ships). One of the aims of this research was to ascertain optimal seating backrest angles for vehicle designers in terms of passenger and operator comfort. However, in addition to comfort, it was considered important to quantify any effects of these backrest angles on operator performance. For example, although a particular backrest angle may produce optimal operator comfort, it may not be operationally viable if this angle resulted in degraded performance.

Static studies of seat backrest angle have shown various responses. Thody et al. (199324. Thody, M., Gregg, V. H. and Edwards, R. J. 1993. "Reclined sitting postures: The effect on human performance of a vigilance task". In Contemporary ergonomics, Edited by: Lovesey, E. J. 28-33. London: Taylor \& Francis. ) investigated the effects of operating whilst reclined $\left(7^{\circ}, 30^{\circ}\right.$ and $60^{\circ}$ from the vertical) over a period of 60 and 70 min. A computer-based vigilance or monitoring task, which consisted of textual messages that appeared on a simulated display, was used to measure reaction times 
and error rates for participants whilst operating at the three angles of recline. No significant effect of seat backrest angle on performance was found.

Edwards et al. (19945. Edwards, R. J., Streets, D. F. and Bond, G. The effects of back angle inclination on target detection. Proceedings of the Human Factors and Ergonomics Society 38th Annual Meeting. pp.1252-1255. ) investigated the effects of seat backrest angles, on a simple target detection task that lasted for $80 \mathrm{~min}$. The time taken to detect a target was unaffected by seat backrest angle, whereas the overall target-detection rate significantly decreased with increasing seat backrest angle. Subjectively reported feelings of discomfort and sleepiness at the body and the neck increased significantly with increasing seat back angle. There were significant differences between $0^{\circ}$ (control) and $65^{\circ}$ from vertical for both self-reported stress increase and arousal decrease with increasing seat backrest angle. The increase in neck discomfort occurred because of the lack of headrest and need to raise the head to view the screen at increasing angle of seat backrest. This may also explain the increase in sleepiness and fatigue levels.

Edmonds (19944. Edmonds, J. 1994. "The effect of reclined sitting posture on hand controlled operations". In Contemporary ergonomics, Edited by: Robertson, S. A. 138143. London: Taylor \& Francis. ) investigated the biomechanical implications of armoured vehicle crew working in reclined positions. It was reported that reclining the crew to reduce the profile of armoured vehicles would result in a substantial number of hand-controlled operations at a level at, or above, shoulder level, thereby imposing unacceptable postural loading on the upper limbs of the crew. Three sitting postures (upright, semi-reclined and reclined) were investigated using electromyography, body discomfort ratings and postural analysis. The results showed significant increases in subjective ratings of discomfort in the upper limbs with an increase in recline, but significant differences were not found in the other measures taken.

There are few studies which have investigated the influence of seat backrest angle on performance during whole-body vibration. The only relevant studies have reported the effects of backrest angle on the transmission of vertical vibration through the human body. Magnusson et al. (199313. Magnusson, M. 1993. Effects of backrest inclination on the transmission of vertical vibrations through the lumbar spine. Clinical

Biomechanics, 8: 5-12. ) demonstrated that the inclination of the backrest only played a minor role in vibration attenuation in the 4-6 Hz range, although Demic et al. (20023. Demic, M., Lukić, J. and Milić, Ž. 2002. Some aspects of the investigation of random vibration influence on ride comfort. Journal of Sound and Vibration, 253(1): 109-129. ) reported that an increase in the backrest angle resulted in an increase in seat-to-head transmissibility over the frequency range $5-25 \mathrm{~Hz}$.

There appears to be a shortage of scientific data relating to the discomfort experienced by people sitting in seats with varying backrest angles. The data presented in current standards (e.g. BS 6841 1987, ISO 2631-1 1997) relate to subjects seated in upright postures. This clearly shows a gap in the knowledge of human exposure to vibration. The study presented in this paper aimed to investigate the effects of the seat backrest angles on performance under different conditions of whole-body vibration. The backrest angles were the same as those used by Paddan et al. (in press) to complement the parallel comfort trial. This approach means that the results can offer 
designers a trade-off between comfort and performance as a function of seat backrest angle during whole-body vibration.

\section{Method}

\subsection{Design}

The trial comprised a repeated-measures Latin-square experimental design, which manipulated two independent variables: seat backrest angle and frequency of wholebody vibration. Participants were exposed to one of four bands of band-limited random oscillations, vertical whole-body vibration: control (no motion), 2-8 Hz, 8-14 $\mathrm{Hz}$ and $14-20 \mathrm{~Hz}$ all at an unweighted vibration magnitude of $2.0 \mathrm{~ms}^{-2}$ r.m.s. The waveforms were generated using broadband random signal and band-limiting filters. These frequency bands were chosen as they represent bands that dominate vertical whole-body vibration on various transport platforms and also encompass the frequencies of the main human resonances. The $2-8 \mathrm{~Hz}$ range should produce the greatest human resonance, followed by $8-14 \mathrm{~Hz}$ and then the $14-20 \mathrm{~Hz}$. The $2-8 \mathrm{~Hz}$ tends to be dominant in land transportation over rough terrain (e.g. cross country), whereas the $14-20 \mathrm{~Hz}$ tends to be dominant in rotary air transportation. There were five backrest angles: $90^{\circ}$ (vertical upright), $67.5^{\circ}, 45^{\circ}, 22.5^{\circ}$ and $0^{\circ}$ (supine). These postures are shown diagrammatically infigure 1 . The dependent variables measured were the objective measures of performance on a choice reaction time (cognitive) task and a tracking (psycho-motor) task, and the subjective measures of workload associated with undertaking these tasks. The experimental protocol was approved by the QinetiQ Ethics Committee under a generic laboratory whole-body vibration exposure protocol.

\subsection{Participants}

Twenty participants ( 10 males and 10 females) took part in the experiment. The mean age of the male participants was 29.0 years ( $S D=10.2$ years, range $21-54$ years), mean mass was $81 \mathrm{~kg}(\mathrm{SD}=11 \mathrm{~kg}$, range $74-95 \mathrm{~kg})$ and mean height was $1.78 \mathrm{~m}$ (SD=0.58 m, range 1.70-1.86 $\mathrm{m}$ ). The mean age of the female participants was 33.8 years ( $\mathrm{SD}=8.5$ years, range $25-47$ years), mean mass was $65.8 \mathrm{~kg}$ ( $S D=8.9 \mathrm{~kg}$, range $54-85 \mathrm{~kg}$ ) and mean height was $1.70 \mathrm{~m}(\mathrm{SD}=0.98 \mathrm{~m}$, range $1.56-1.89 \mathrm{~m})$. Subjects were in good health with no history of back or gastrointestinal disorders.

\subsection{Apparatus}

A man-rated Servotest vertical vibrator with a displacement of up to $\pm 0.9 \mathrm{~m}$ was used to generate the vibration stimuli. The vibrator has a velocity limit of $1.5 \mathrm{~ms}^{-1}$, an acceleration limit of $30 \mathrm{~ms}^{-2}$ and a frequency range of $0-50 \mathrm{~Hz}$.

An adjustable seat was mounted on the platform of the vertical vibrator.Figure 2 presents a schematic view of the experimental setup. The main frame for the adjustable seat was of a rigid wooden construction consisting of a seven-layer $23 \mathrm{~mm}$ plywood. The seat measured $2.0 \times 0.8 \times 1.5 \mathrm{~m}$ high with backrest fully upright and incorporated an adjustable footrest, a three-point safety harness, a chest strap and a motorised backrest that could be driven remotely to any angle between $0^{\circ}$ (recumbent) and $90^{\circ}$ (upright). 
The seat surface was covered in 1-mm-thick foam rubber, and the participants had the use of a small cushion headrest measuring $0.22 \times 0.15 \times 0.35 \mathrm{~m}$. The vertical acceleration at the base of the seat was measured using an Endevco Q-Flex QA-116-15 servo accelerometer. Additional orthogonal acceleration measurements were also taken from the mid-point on the rear of the backrest using Endevco 7265-10 piezoresistive accelerometers. Participant intercom and emergency stop controls were also provided.

Information was presented on a TFT liquid crystal display (LCD) that was rigidly mounted on the platform. This displayed information for the tracking and detection tasks. The display was $255 \mathrm{~mm}$ wide and $190 \mathrm{~mm}$ high and approximately $600 \mathrm{~mm}$ from the eyes of the participant. The numbers in the detection task subtended an angle of approximately $0.2^{\circ}$ of arc at the eyes of the subjects. This is equivalent to reading text of 10-point size at about $600 \mathrm{~mm}$ distance; similar experimental setups have been used elsewhere (e.g. Lewis and Griffin, 198012. Lewis, C. H. and Griffin, M. J. 1980. Predicting the effects of vibration frequency and axis, and seating conditions on the reading of numeric displays. Ergonomics, 23: 485-501. ). The characters were presented using a $5 \times 7$ pixel dot matrix; the height of characters on the screen was about $2 \mathrm{~mm}$.

To maintain a consistent and optimal positioning of the screen relative to the occupant, the display was attached to the backrest: when the backrest was reclined, the display remained in the same relative position to the eyes of the operator. The frame used to mount the screen to the backrest was rigid, therefore producing the same vibration exposure of the display as that entering the seated human body.

A four-button response box was used to record subject responses in the choice reaction time task. The button box was rigidly mounted to the seat on an adjustable mount that enabled it to be positioned close to the body, in a central position, to maintain neutrality of the shoulder, upper and lower arm for each participant. The participants were also able to grip either side of the button box with both hands to stabilise their motor responses.

In addition, a joystick was mounted beside the participant, the side depending on the handedness of the participant. As with the button box, it was adjustable to enable standardised neutrality of the shoulder, upper and lower arm for each participant.

\subsection{Tasks}

In the choice reaction time task (Totterdell and Folkard 199225. Totterdell, P. and Folkard, S. 1992. In situ repeated measures of affect and cognitive performance facilitated by use of a hand-held computer. Behavior Research Methods, Instruments, and Computers, 24(4): 545-553. , Shingledecker 198422. Shingledecker, C. A. 1984. A task battery for applied human performance assessment research. Wright-Patterson Air Force Base, OH: Air Force Aerospace Medical Research Laboratories. Report No. AFAMRL-TR-84-071. ), the participants were asked to respond to a series of individual numbers from ' 2 ' to ' 5 ' that appeared randomly on the screen. The numbers were grouped into two, in that ' 2 ' or ' 3 ' were 'low numbers' and ' 4 ' or ' 5 ' were 'high numbers'. A high number appearing on the left of the screen signified that the top button on the left of the button box should be pressed, and a low number on the left signified that the lowest button on the left of the button box should be pressed. 
Conversely, for numbers on the right, the logic was reversed, such that high numbers were linked to the bottom right button, and low numbers to the upper right button. The numbers were presented for a maximum of $1 \mathrm{~s}$. The subjects undertook the task for $3 \mathrm{~min}$. The output was the number of correct, incorrect and missed responses and the participants' reaction times.

The (unstable) tracking task (Shingledecker 198422. Shingledecker, C. A. 1984. A task battery for applied human performance assessment research. Wright-Patterson Air Force Base, OH: Air Force Aerospace Medical Research Laboratories. Report No. AFAMRL-TR-84-071. ) was used to assess perceptual-motor control. Participants used the joystick to centralise a horizontally moving cross within a fixed target area, displayed in the centre of a monitor. Participant input produces error, which is magnified by the system so that it is increasingly necessary to respond to the velocity and the position of the cross. Participants undertook the task for $3 \mathrm{~min}$. The output was the total number of boundary hits (referred to as 'out-of-range' measure) and the average error score. Once a boundary hit had occurred, the subject recovered by manoeuvring the cross back to the middle of the screen. The average error was proportional to the distance of the cross from the target area (r.m.s.) and was measured in arbitrary units.

NASA-TLX workload rating scales were used as a subjective measure of workload (Hart and Staveland 1988). These consist of six sub-scales (physical demand, mental demand, frustration, effort, temporal workload and perceived performance) from which an overall workload score can be derived. The global score allows a comparison to be made between the different conditions, but the sub-scales enable further analysis to be conducted to determine how the combination of task and conditions affected participants' ability to complete the task. For example, performance on a task may be maintained during difficult ambient conditions only if participants increase their mental or physical effort. The NASA-TLX was administered between each task, that is, after the tracking task and again after the choice reaction time task to enable each type of task to be assessed in terms of workload as a separate entity.

\subsection{Procedure}

The participants attended the laboratory once a day for six days. The first day comprised pre-trial training on the tasks to plateau level of performance (to minimise learning effects) and familiarisation with the experimental equipment, set-up, procedure and requirements. The successive five days comprised the five experimental sessions where participants were exposed to all four frequencies of vibration, $0 \mathrm{~Hz}$ (no vibration), $2-8 \mathrm{~Hz}, 8-14 \mathrm{~Hz}$ and $14-20 \mathrm{~Hz}$ at $2.0 \mathrm{~ms}^{-2}$ r.m.s. whole-body vertical vibration at one of the seat backrest angles $90^{\circ}$ (upright), $67^{\circ} 45^{\circ}, 22^{\circ}$ and $0^{\circ}$ (supine). The order of backrest angle was determined by the Latin-square design, whereas the order of whole-body vibration exposure was randomised within each experimental session.

The acceleration level and frequencies of whole-body vibration exposure used in the trial limited the total duration of whole-body vibration exposure during each session to $18 \mathrm{~min}$. This was chosen to comply with the British Standard 6841 (1987) guideline limits for whole-body vibration exposure of a vibration dose value (VDV) of $15 \mathrm{~ms}^{-1.75}$ 
whilst ensuring sufficient amplitude of whole-body vibration exposure (i.e. to realistic acceleration levels that could adversely affect performance).

For each experimental session, the participants attended the laboratory at the same time of day to control for any diurnal effects on performance. The participants were briefed on the procedure and requirements of the trial before being seated on the vertical vibration platform at one of the seat backrest angles. On arrival at the laboratory, participants sat on the seat at the appropriate backrest angle. The footrest and the participant's feet were positioned so that the leg angle at the knee was fixed at $120^{\circ}$ for all conditions. The participants were then secured to the seat by the threepoint harness, and headphones placed on the head and the headrest adjusted. The headphones allowed two-way communication with the experimenter and also conveyed pink noise (65 $\mathrm{dB}(\mathrm{A})$ at the ear) to mask the noise of the vertical oscillator in operation.

When the participants signalled their readiness the first whole-body vibration exposure condition began. Participants immediately undertook the tracking task for 3 min. When the task was completed the whole-body vibration ceased and participants completed the NASA-TLX scales, which took approximately $1 \mathrm{~min}$. The participants were then exposed to the same whole-body vibration condition whilst they undertook the choice reaction time task for three minutes. On completion of this task, the wholebody vibration ceased, and the participants again completed the NASA-TLX scales. There was a short break of approximately 2-3 min where participants remained on the platform before the whole procedure was repeated for the next whole-body vibration condition. The experimental session therefore lasted approximately 30-40 min.

An analysis of variance (ANOVA) technique was used to test for any significant effects of the independent variables (vibration frequency and backrest angle) on the dependant variables (performance and workload). The Newman-Keuls post-hoc test was also used to further investigate the nature of any significant effects found in the ANOVA.

\section{Results}

\subsection{Objective Measures: Effects of backrest angle and vibration frequency on tracking performance}

\subsubsection{Out-of-limits score}

There was a general trend for the out-of-limits score to be greater (i.e. poorer performance) for the vibration conditions compared to the control condition (seeFigure 3). The analysis showed a significant effect of vibration frequency ( $F=13.78$, $\mathrm{df}=3,57, p<0.001$ ) on out-of-limits performance. Performance whilst exposed to 2-8 $\mathrm{Hz}$ and $8-14 \mathrm{~Hz}$ vibration was poorer compared to the control condition at all backrest angles $(p<0.001)$.

The analysis also indicated a significant backrest angle effect $(F=5.13, \mathrm{df}=4,75, p<$ 0.01 ). The post-hoc test showed that the $22^{\circ}$ backrest angle produced poorer performance than the other backrest angles $(p<0.001)$. 


\subsubsection{Tracking Error}

The tracking error data showed a similar trend to the out-of-limits data: the tracking errors were greater (i.e. poorer performance) for the vibration conditions compared to the control condition (Figure 4). The analysis showed a significant effect of vibration frequency on tracking error $(\mathrm{F}=15.23, \mathrm{df}=3,57, p<0.001)$. Post-hoc analysis showed that performance was poorer during the $2-8 \mathrm{~Hz}$ condition compared to the control and $14-20 \mathrm{~Hz}$ conditions $(p<0.01)$.

A effect of seat backrest angle $(\mathrm{F}=4.97, \mathrm{df}=4,75, p<0.01)$ and interaction between frequency and seat backrest angle $(\mathrm{F}=1.90, \mathrm{df}=12,228, p<0.05)$ on tracking error were also found. Within the $90^{\circ}$ backrest angle, the post-hoc test showed that $2-8 \mathrm{~Hz}$ vibration tracking error performance was worse than the control condition $(p<0.01)$. Within the $67^{\circ}$ backrest angle, performance whilst exposed to $2-8 \mathrm{~Hz}$ vibration was degraded compared to the $14-20 \mathrm{~Hz}$ and control conditions $(p<0.01)$. Within the $45^{\circ}$ backrest angle, performance was better during the $14-20 \mathrm{~Hz}$ condition compared to the control condition $(p<0.05)$ and the $2-8 \mathrm{~Hz}$ and $8-14 \mathrm{~Hz}$ conditions $(p<0.01)$. Within the $22^{\circ}$ backrest angle, the control condition resulted in better performance compared to all the vibration conditions: the $2-8 \mathrm{~Hz}$ and $8-14 \mathrm{~Hz}$ condition $(p<0.01)$ and the $14-20 \mathrm{~Hz}$ condition $(p<0.05)$.

Within the control condition (no vibration), the $90^{\circ}$ backrest angle resulted in a better performance than at $45^{\circ}$ or $22^{\circ}$ backrest angle $(p<0.01)$. Within the $8-14 \mathrm{~Hz}$ condition, the $90^{\circ}$ and $67^{\circ}$ backrest angles also produced better levels of performance compared to the $22^{\circ}$ backrest angle $(p<0.05)$. Within the $14-20 \mathrm{~Hz}$ condition, $22^{\circ}$ backrest angle resulted in poorer performance than all other backrest angles: the $45^{\circ}$ backrest angle $(p<0.001)$ and the $90^{\circ}, 67^{\circ}$ and $0^{\circ}$ backrest angles $(p<0.01)$.

\subsection{Objective Measures: Effects of backrest angle and vibration frequency on choice reaction time performance}

\subsubsection{Reaction time}

Reaction times were longer for the choice reaction time tasks with vibration than the control (no vibration, seeFigure 5 ). The analysis showed a significant effect of vibration frequency $(\mathrm{F}=8.35, \mathrm{df}=3,57, p<0.001)$ on correct reaction time performance, but no effect of backrest angle on correct reaction time performance. Reaction times were faster in the control condition compared to the $2-8 \mathrm{~Hz}$ condition $(p<0.01)$, the 8-14 $\mathrm{Hz}$ and $14-20 \mathrm{~Hz}$ vibration conditions $(p<0.001)$.

\subsubsection{Percentage incorrect}

No significant effect of vibration frequency or backrest angle was found for the percentage incorrect measure.

\subsubsection{Percentage missed}

No significant effect of vibration frequency or backrest angle was found for the percentage missed measure. 


\subsection{Subjective Measures: Effects of backrest angle and vibration frequency on tracking workload}

\subsubsection{Mental demand}

No significant effect of vibration frequency or backrest angle was found for the mental workload measure for the tracking task.

\subsubsection{Physical demand}

Physical demand was generally rated as being greater for all the vibration conditions when compared to the control condition for the tracking task (seeFigure 6). The analysis showed a significant effect of vibration ( $\mathrm{F}=10.73, \mathrm{df}=3,57, p<0.001)$ on physical demand workload. Physical demand workload was perceived to be lower during the stationary control condition compared to all of the vibration conditions: 2-8 $\mathrm{Hz}(p<0.001), 8-14 \mathrm{~Hz}(p<0.001)$ and $14-20 \mathrm{~Hz}(p<0.05)$.

\subsubsection{Temporal demands}

There was a significant effect of vibration frequency $(\mathrm{F}=3.71, \mathrm{df}=3,57, p<0.05)$ on temporal demand workload for the tracking task. Temporal demand workload was perceived to be lower during the stationary control conditions compared to the three vibration conditions ( $p<0.05$, seeFigure 7$)$.

\subsubsection{Performance}

Mean subjective ratings of performance for the tracking task were generally higher for the control condition than for the vibration conditions (Figure 8). The analysis showed a significant effect of vibration frequency $(\mathrm{F}=3.71, \mathrm{df}=3,57, p<0.05)$ on subjective ratings of perceived performance. The participants rated their performance to be better under the stationary control condition compared to the $2-8 \mathrm{~Hz}$ and $8-14 \mathrm{~Hz}$ vibration conditions $(p<0.01)$.

\subsubsection{Effort}

The analysis showed a significant effect of vibration frequency $(\mathrm{F}=3.00, \mathrm{df}=3,57, p<$ 0.05 ) on subjective effort scores for the tracking task.

\subsubsection{Frustration}

The analysis showed a significant effect of vibration frequency $(\mathrm{F}=2.91, \mathrm{df}=3,57, p<$ 0.05 ) on subjective effort scores for the tracking task (Figure 9). However, the post-hoc tests did not reveal a source of this main effect.

\subsection{Subjective Measures: Effects of backrest angle and vibration frequency on choice reaction time workload}

\subsubsection{Mental demand}

Mental demand was generally rated as being greater for the vibration conditions when compared to the control condition for the choice reaction time task (seeFigure 10). There was a significant effect of vibration frequency $(\mathrm{F}=6.39, \mathrm{df}=3,57, p<0.001)$ on mental demand workload. Mental workload was rated lower during the control condition compared to the $2-8 \mathrm{~Hz}$ and $8-14 \mathrm{~Hz}$ vibration conditions $(p<0.01)$. 


\subsubsection{Physical demand}

Physical demand was generally rated as being lower for the control condition when compared to the vibration condition for the choice reaction time tasks (seeFigure 11). The analysis showed a significant effect of vibration frequency ( $\mathrm{F}=14.86, \mathrm{df}=3,57, p<$ 0.001 ) on physical demand workload. Physical demand workload was rated lower during the control condition compared to all the vibration conditions $(p<0.001)$. In addition, Figure 11 shows that physical workload during the $14-20 \mathrm{~Hz}$ condition was rated lower than the other two vibration conditions $[2-8 \mathrm{~Hz}, 8-14 \mathrm{~Hz}(p<0.05)]$.

\subsubsection{Temporal demands}

There was a significant effect of vibration $(\mathrm{F}=9.20, \mathrm{df}=3,57, p<0.001)$ on temporal demand workload for the choice reaction time task. Temporal demand workload was rated lower during the control condition compared to all the vibration conditions ( $p<$ 0.01). In addition, temporal demand workload at 2-8 $\mathrm{Hz}$ was rated higher than the other vibration conditions ( $p<0.05$, seeFigure 12 ).

\subsubsection{Performance}

The analysis showed a significant interaction between frequency and backrest angle $(\mathrm{F}=1.90, \mathrm{df}=12,228, p<0.05)$ on ratings of subjective performance for the choice reaction time task (seeFigure 13 ).

For the $45^{\circ}$ backrest angle, perceived performance ratings were worse for the 14-20 $\mathrm{Hz}$ condition compared to the stationary control condition $(p<0.05)$. In addition, performance ratings were significantly worse at $14-20 \mathrm{~Hz}$ compared to $8-14 \mathrm{~Hz}$ ( $p<$ $0.05)$. Within the control condition of no vibration, the $45^{\circ}$ backrest angle resulted in significantly higher ratings of perceived performance compared to $0^{\circ}$ backrest angle ( $p$ $<0.05$, seeFigure 13 ).

\subsubsection{Effort}

Mean ratings of effort were greater for all the vibration conditions when compared to the control condition for the choice reaction time task (seeFigure 14). The analysis showed a significant effect of vibration frequency $(F=6.42, \mathrm{df}=3,57, p<0.001)$ on subjective ratings of perceived effort. Perceived effort was lower during the control condition compared to the vibration conditions: $2-8 \mathrm{~Hz}(p<0.001), 8-14 \mathrm{~Hz}$ and $14-20$ $\mathrm{Hz}(p<0.05)$.

\subsubsection{Frustration}

The analysis showed a significant effect of vibration frequency $(F=3.64, \mathrm{df}=3,57, p<$ 0.05 ) on frustration for the choice reaction time task. Frustration during the stationary control condition was lower than that during the $2-8 \mathrm{~Hz}$ vibration condition $(p<0.01)$.

\section{Discussion and conclusions}

The aim of this study was to ascertain and quantify any effects of the interaction between seat backrest angle and whole-body vibration on indices of performance related to tasks undertaken in a vehicle environment. It is important to reiterate that the effects of whole-body vibration on task performance requiring vision and handarm control are dependent on many factors including size of display image/font, distance from operator to the display, sensitivity of controls, distance of reach to 
controls, frequency and amplitude of whole-body vibration. The results from the study can therefore only be interpreted within the constraints of the tasks and configuration used. Variation of any of these factors may have produced different results. The position of the screen remained the same relative to the occupant, that is, when the backrest was reclined, the display remained in the same relative position to the eyes of the operator. If the backrest was reclined independently of the display set-up (i.e. if this remained set in one position only), then it is very likely that different results would have been found. However, the optimal design of the set-up used for this experiment was to minimise the effects of these additional variables on the results and outcome.

The overall results of this experiment have shown no effects of seat backrest angle on the cognitive (choice reaction time) task, indicating that seat backrest angle under varying conditions of whole-body vibration does not adversely affect cognitive performance. It is important to note here that the experimental set-up for the cognitive task was designed to minimise the biomechanical effects of the whole-body vibration on performance of the task so that any detriments in performance could be attributed mainly to cognitive effects and not dominated by biomechanical effects. For example, the stimulus text presented on the display was sufficiently large to not be too difficult to read during whole-body vibration. (The text size was $2 \mathrm{~mm}$ high subtending an angle of $0.2^{\circ}$ at the eye.) As the seat backrest reclines, the path of vibration transmission from the contact surface to the head changes from being primarily through the musculo-skeletal system to directly into the skull. This may cause a different resonance of the eyeballs producing perceived blurring of the display. (Motion of the eyeballs would be predominantly in the chin-to-crown direction of the head with the subjects seated in a $90^{\circ}$ posture, whereas the motion would change to the nose-to-back of head direction with the subjects in a $0^{\circ}$ posture. The effect on eyeball resonances of such changes in posture is not known.) However, this may only occur if the magnitude of whole-body vibration is sufficiently large or the mode of vibration is excited (that is, the natural frequency). Furthermore, in this study, the head was supported on a small cushion such that the vibration at the head would have been different to the vibration at the back. It is worth noting that ISO 2631-1 (1997) states that frequency weighting Wj should be used to assess vibration at the head for a person in a recumbent (supine) posture. Although it is clear from the standard that Wj should not be used when the body is vertical, it seems somewhat arbitrary that Wj should not be used when the backrest is inclined at an angle of $22.5^{\circ}$ to the horizontal. The relationship between vision, visual performance and whole-body vibration frequency and amplitude at the head has not been quantified. In addition, in terms of hand-arm control, the participants were holding onto the button box with both hands and only needed to make minimal dextrous movements of the thumb to enter their response. If this parameter was altered so that participants had to actively reach out to enter their response, the results would most likely suggest poorer performance (Paddan and Griffin 1995), but these would reflect difficulty with hand-arm coordination and not with cognition per se.

The results from the tracking task generally suggest that a seat backrest angle of $22^{\circ}$ produces poorer psycho-motor (tracking) task performance than the other seat backrest angles under all conditions (stationary control and whole-body vibration). It is not immediately apparent why this particular seat backrest angle should adversely affect tracking performance. As with vision, the biodynamic effects of whole-body 
vibration and seat backrest angle on the transmission of vibrations to the hands and arms have not been quantified. It is possible that there may be some trade-off between backrest angle and transmissibility. For example, at the upright $\left(90^{\circ}\right)$ seat angle it may be expected that the $2-8 \mathrm{~Hz}$ would have produced greater performance decrements than at backrest angles moving towards the supine. This is because at the $90^{\circ}$ backrest angle the whole-body vibration enters the buttocks and is amplified by the body due to the upright posture (Paddan and Griffin 198820. Paddan, G. S. and Griffin, M. J. 1988. The transmission of translational seat vibration to the head. I. Vertical seat vibration. Journal of Biomechanics, 21: 191-197. ). As the body moves out of the axis of vibration, the vibration input is no longer directly entering the body through the buttocks but is more evenly spread through the body. However, for frequencies around and above $14 \mathrm{~Hz}$, where the eyeballs resonate within the skull, decreasing backrest angle towards the supine brings the head more into the direct axis of whole-body vibration input (which at the $90^{\circ}$ backrest angle would have been attenuated by the trunk). The results of the tracking task initially appear to (tentatively) support this 'trade-off' hypothesis, as shown by the trend of the lines illustrated inFigure 4. Less erroneous performance occurred at the more upright seating angles at $8-14 \mathrm{~Hz}$ and $14-20 \mathrm{~Hz}$ than at other backrest angles. However, if the hypothesis was true then it would be expected that performance would have been poorer still at $0^{\circ}$ when the head is directly in the axis of vertical vibration. In addition, although not significant, errors on the tracking task peak within the $2-8 \mathrm{~Hz}$ condition at $22^{\circ}$ and not at $90^{\circ}$.

One of the clearest results from the study was that whole-body vibration, especially in the bandwidth 2-8 Hz, had a detrimental effect on both tracking performance overall and reaction times for the cognitive task relative to the stationary control condition. This was to be expected as the frequency ranges of whole-body vibration used incorporated the human resonance frequency range and that these resonances occur in the $2-8 \mathrm{~Hz}$ frequency range. These results show that whole-body vibration and its adverse effects on vision and hand-arm control increases task difficulty. These objective results were reinforced by the subjective NASA-TLX ratings of workload. The participants rated the tasks as requiring more overall effort, more mentally and physically demanding and more frustrating to achieve compared to the stationary control conditions. In addition, they rated their perceived performance as poorer during whole-body vibration conditions relative to the control condition. Overall, the results suggest that whole-body vibration made the tasks more difficult to achieve, which was probably due to the increased difficulty in the visual and hand-arm/manual control elements of the task. However, the subjective data strongly suggests that the participants overcame this difficultly by increasing effort. These results agree with findings from an experiment to investigate performance and workload in twisted postures (Newell and Mansfield 200817. Newell, G. S. and Mansfield, N. J. 2008. Evaluation of reaction time performance and subjective workload during whole-body vibration exposure whilst seated in upright and twisted postures with and without armrests. International Journal of Industrial Ergonomics, 38(5-6): 499-508. ). Reaction time decrements were small, whilst workload increased significantly for increased postural and/or vibrational loading. As increased workload/effort is associated with earlier onset of detriments caused by fatigue in overnight experiments (Spencer et al. 199823. Spencer, M. B., Rogers, A. S. and McGown, A. S. 1998. The effects of task 
rotation on sustained overnight performance (UKR) DERA/CHS/PP5/98/0081/1.0), this study indicates that performance in fixed base simulators (e.g. battlefield simulation) might be overestimated compared to real performance on a real moving platform.

To summarise, with the exception of the $22^{\circ}$ seat backrest angle for the tracking task, seat backrest angle did not adversely affect performance during whole-body vibration. However, these results must be interpreted in the context of the experiment design. The tasks lasted only 3 min each due to the requirement to expose participants to realistic levels of whole-body vibration within the current daily guideline limits. In addition, the experimental configuration was such that whole-body vibration biodynamic effects were minimised. Variation of the type of task, display set-up, control set-up, amplitude of whole-body vibration and duration of task/whole-body vibration could produce different results. It is important to note that this type of investigation has not been completed before and it was important to control as many factors as possible. The main finding from the trial was the increased effort made by participants to maintain performance during whole-body vibration relative to a stationary control condition. Potentially, these results suggest that undertaking tasks in a moving (whole-body vibration) environment could increase workload and the risk of earlier onset of fatiguing effects on performance. Future trials could investigate the influence of display and control parameters as well as task duration.

\section{References}

1. British Standards Institution. 1987. "BS 6841. Measurement and evaluation of human response to whole-body mechanical vibration and repeated shock". London: British Standards Institution.

2. Corbridge, C. and Griffin, M. J. 1991. Effect of vertical vibration on passenger activities: writing and drinking. Ergonomics, 34(10): 1313-1332.

3. Demic, M., Lukić, J. and Milić, Ž. 2002. Some aspects of the investigation of random vibration influence on ride comfort. Journal of Sound and Vibration, 253(1): 109-129.

4. Edmonds, J. 1994. "The effect of reclined sitting posture on hand controlled operations". In Contemporary ergonomics, Edited by: Robertson, S. A. 138-143. London: Taylor \& Francis.

5. Edwards, R. J., Streets, D. F. and Bond, G. The effects of back angle inclination on target detection. Proceedings of the Human Factors and Ergonomics Society 38th Annual Meeting. pp.1252-1255.

6. Griffin, M.J. 1990. Handbook of human vibration, London: Academic Press.

7. Hart, S. G. and Staveland, L. E. 1988. "Development of a NASA-TLX (Task Load Index): results of empirical and theoretical research". In Human mental workload, Edited by: Hancock, P. A. and Meshkati, N. Amsterdam: Elsevier Science Publishers B.V.

8. International Organisation for Standardisation. 1997. "ISO 2631. Mechanical vibration and shock-evaluation of human exposure to whole-body vibration Part 1: General requirements". 
9. Jex, H. R. and Magdaleno, R. E. 1978. Biomechanical models for vibration feedthrough to hands and head for a semisupine pilot. Aviation, Space and Environmental Medicine, Section II, 49: 304-316.

10. Jex, H. R. and Magdaleno, R. E. Progress in measuring and modelling the effects of low frequency vibration on performance. AGARD Conference Proceedings CP 253: Models and Analogues for the Evaluation of Human Biodynamic Response, Performance and Protection. November6-101978, Paris. Edited by: von Gierke, H. E. Paper A29

11. Lewis, C. H. and Griffin, M. J. 1978. A review of the effects of vibration on visual acuity and continuous manual control. II: Continuous manual control. Journal of Sound and Vibration, 56(3): 415-457.

12. Lewis, C. H. and Griffin, M. J. 1980. Predicting the effects of vibration frequency and axis, and seating conditions on the reading of numeric displays. Ergonomics, 23: 485-501.

13. Magnusson, M. 1993. Effects of backrest inclination on the transmission of vertical vibrations through the lumbar spine. Clinical Biomechanics, 8: 5-12.

14. Mansfield, N. J. 2005. Human response to vibration, Boca Raton, FL: CRC Press.

15. McLeod, R. W. and Griffin, M. J. 1989. A review of the effects of whole-body translational vibration on continuous manual control performance. Journal of Sound and Vibration, 133: 55-115.

16. Moseley, M. J., Lewis, C. H. and Griffin, M. J. 1982. Sinusoidal and random whole-body vibration: comparative effects on visual performance. Aviation, Space and Environmental Medicine, 53: 1000-1005.

17. Newell, G. S. and Mansfield, N. J. 2008. Evaluation of reaction time performance and subjective workload during whole-body vibration exposure whilst seated in upright and twisted postures with and without armrests. International Journal of Industrial Ergonomics, 38(5-6): 499-508.

18. Paddan, G. S. Hand movements during exposure to lateral seat vibration. UK Group Meeting on Human Response to Vibration, APRE, Farnborough. September1993.

19. Paddan, G. S. in press. The influence of seat backrest angle on perceived discomfort during exposure to vertical whole-body vibration. Ergonomics,

20. Paddan, G. S. and Griffin, M. J. 1988. The transmission of translational seat vibration to the head. I. Vertical seat vibration. Journal of Biomechanics, 21: 191-197.

21. Paddan, G. S. and Griffin, M. J. Interruption in hand control during exposure to whole-body vertical vibration. Ergonomics Society Annual Conference, University of Kent at Canterbury. April4-61995. Edited by: Robertson, S. A. pp.518-523. London: Taylor and Francis.

22. Shingledecker, C. A. 1984. A task battery for applied human performance assessment research. Wright-Patterson Air Force Base, $\mathrm{OH}$ : Air Force Aerospace Medical Research Laboratories. Report No. AFAMRL-TR-84-071. 
23. Spencer, M. B., Rogers, A. S. and McGown, A. S. 1998. The effects of task rotation on sustained overnight performance (UKR)

DERA/CHS/PP5/98/0081/1.0

24. Thody, M., Gregg, V. H. and Edwards, R. J. 1993. "Reclined sitting postures: The effect on human performance of a vigilance task". In Contemporary ergonomics, Edited by: Lovesey, E. J. 28-33. London: Taylor \& Francis.

25. Totterdell, P. and Folkard, S. 1992. In situ repeated measures of affect and cognitive performance facilitated by use of a hand-held computer. Behavior Research Methods, Instruments, and Computers, 24(4): 545-553.

26. Wang, X. and Trasbot, J. 2011. Effects of target location, stature and hand grip type on in-vehicle reach discomfort. Ergonomics, 54(5): 466-476.

27. Yau, Y. J., Chao, C. J., Feng, W. Y. and Hwang, S. L. 2011. The effects of platform motion and target orientation on the performance of trackball manipulation. Ergonomics, 54(8): 745-754. 

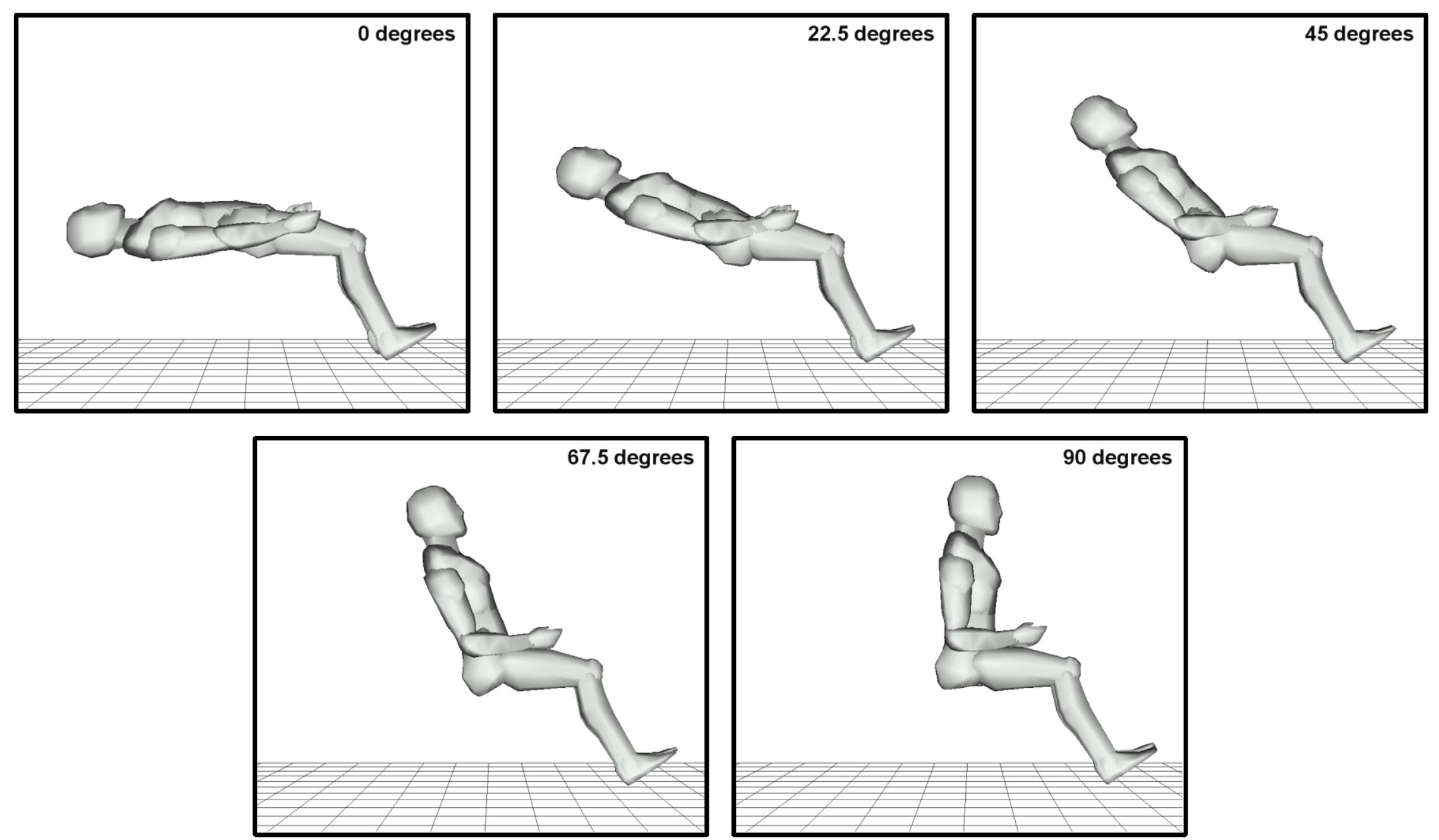

Figure 1 The five postures used in the experiments illustrating the changes in backrest angle ('0 $0^{\circ}$ supine', ' $90^{\circ}$ upright'). 


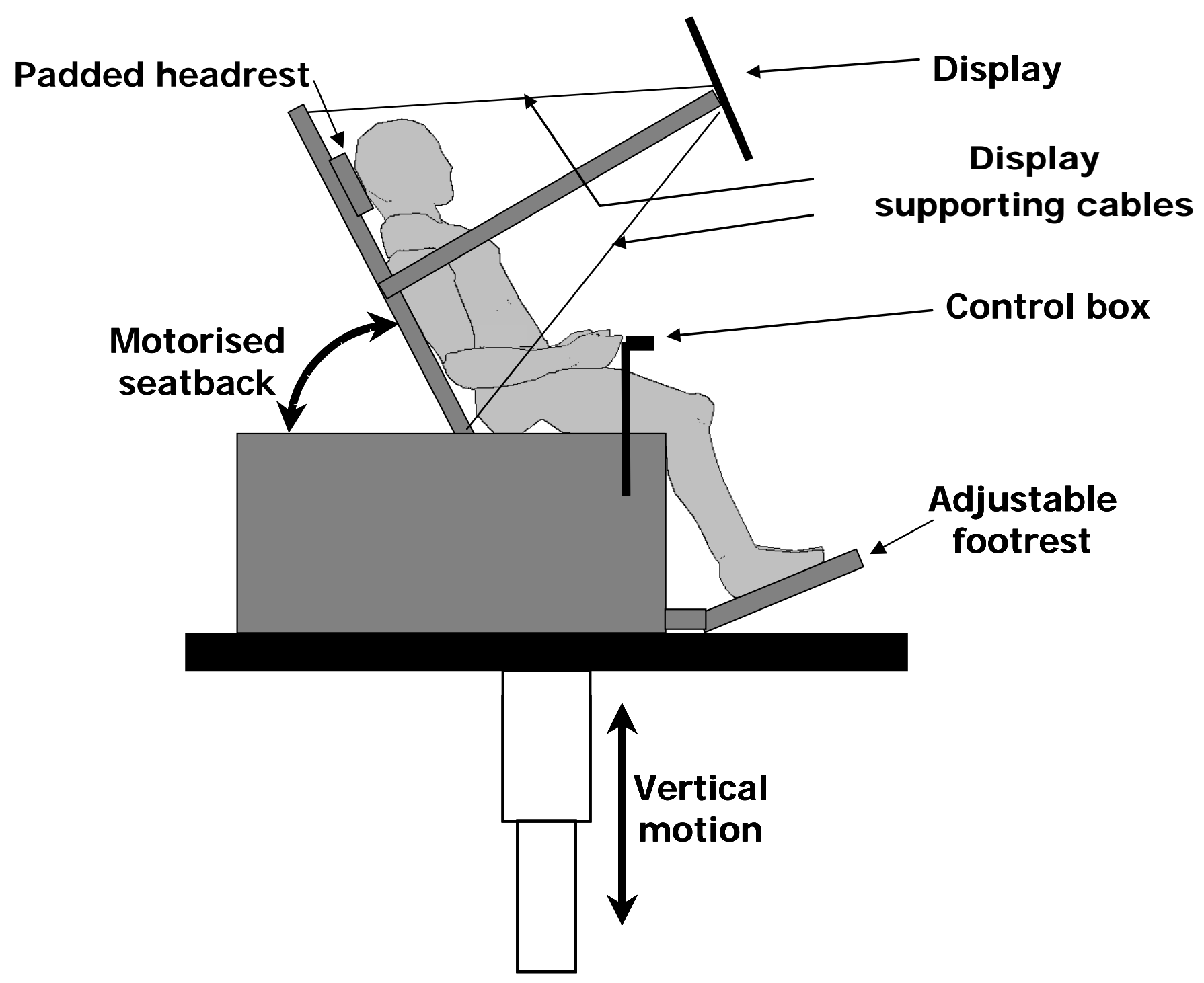


Figure 2 Apparatus used in the experiment, showing the $67.5^{\circ}$ backrest angle condition.

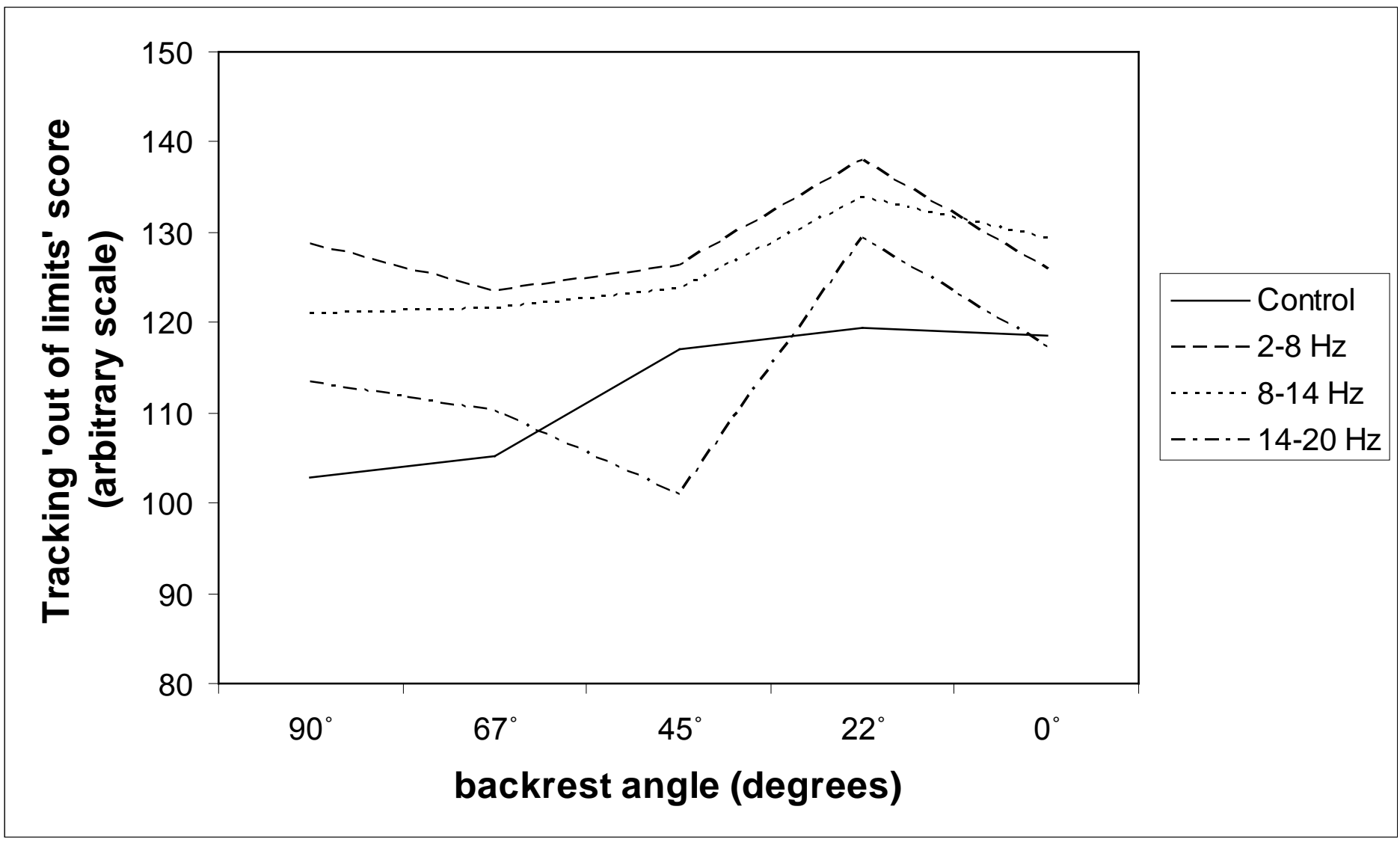

Figure 3 Mean tracking 'out-of-limits' score as a function of backrest angle for the three vibration conditions and the control condition (' $0{ }^{\circ}$ supine', ' $90^{\circ}$ upright'). 


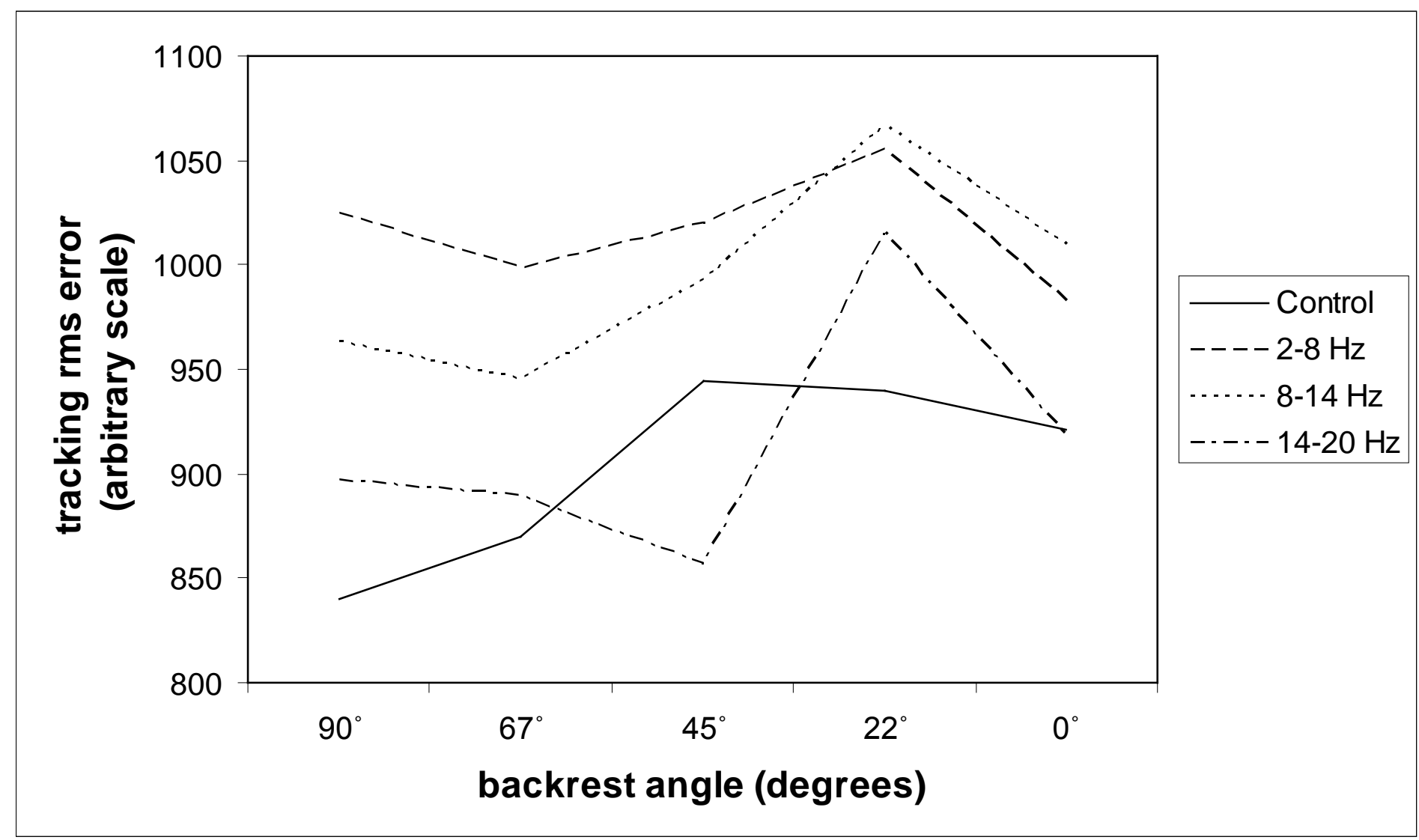

Figure 4 Mean tracking error as a function of backrest angle for the three vibration conditions and the control condition (' $0{ }^{\circ}$ supine’, ' $90^{\circ}$ upright'). 


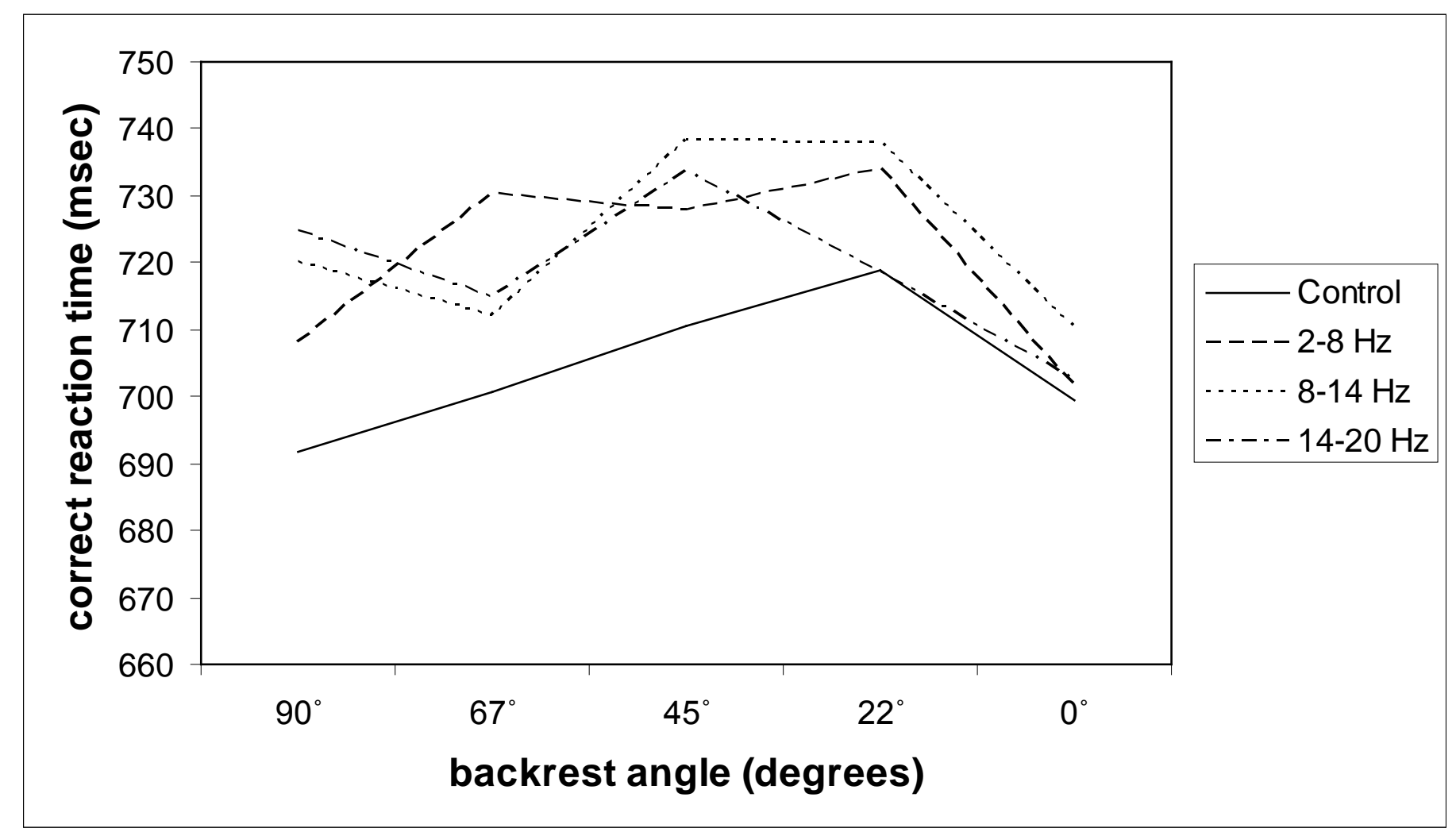

Figure 5 Mean reaction time for correct responses as a function of backrest angle for the three vibration conditions and the control condition (' $0^{\circ}$ supine', ' $90^{\circ}$ upright'). 


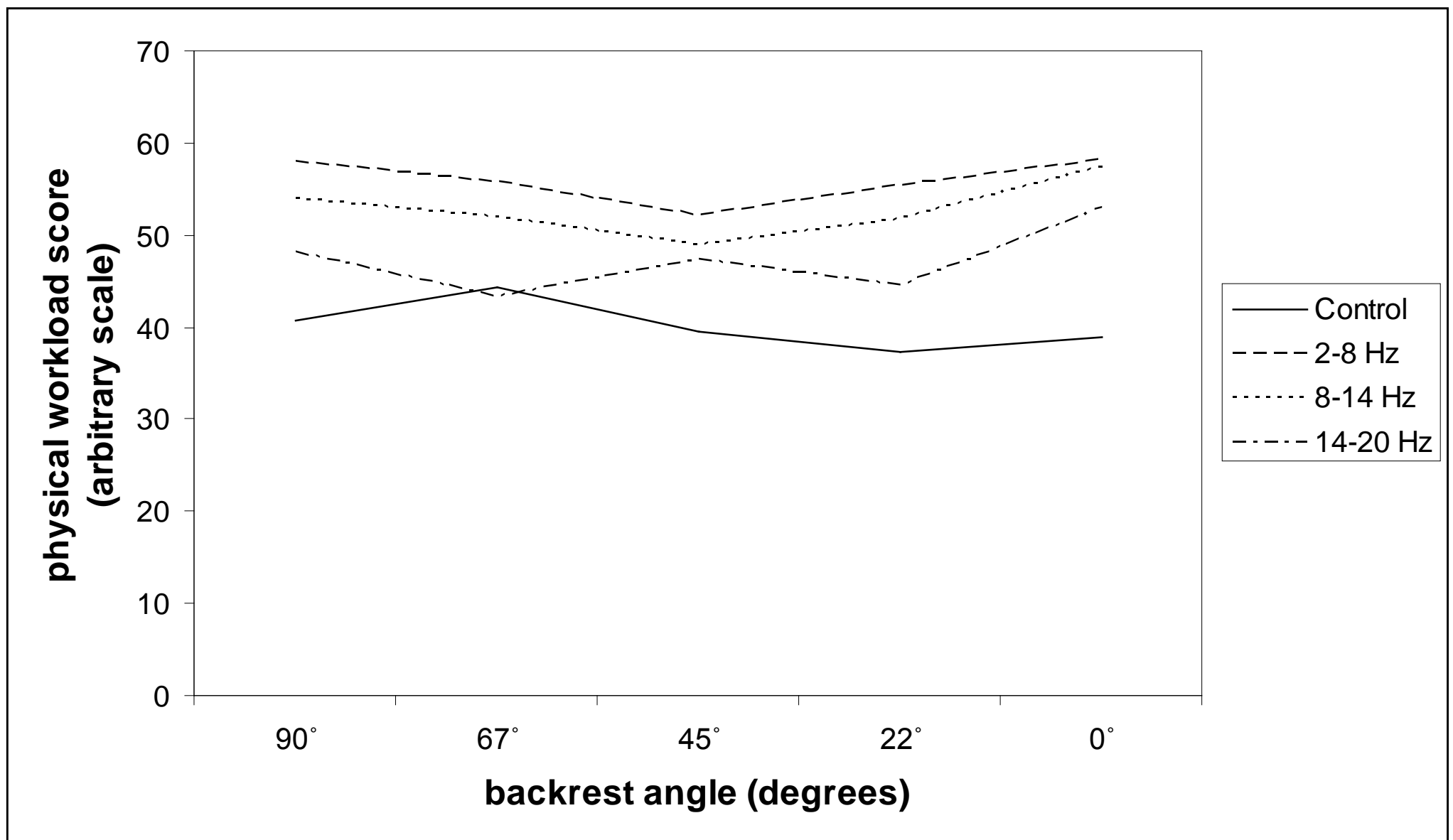

Figure 6 Mean perceived physical workload ratings as a function of backrest angle for the three vibration conditions and the control condition, during the tracking task (' $0{ }^{\circ}$ supine', ' $90^{\circ}$ upright'). 


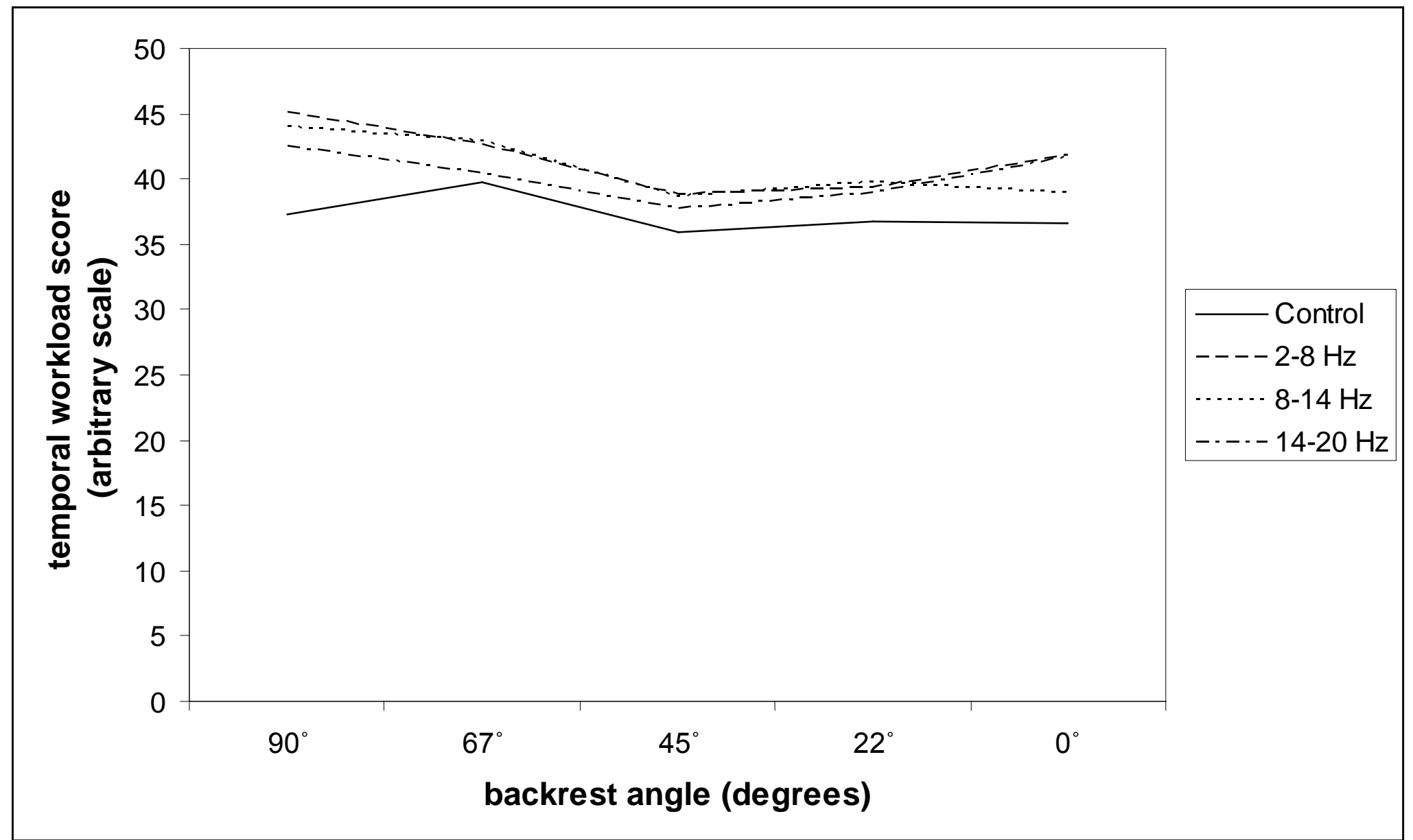

Figure 7 Mean perceived temporal workload as a function of backrest angle for the three vibration conditions and the control condition, for the tracking task (' 0 supine', ' $90^{\circ}$ upright'). 


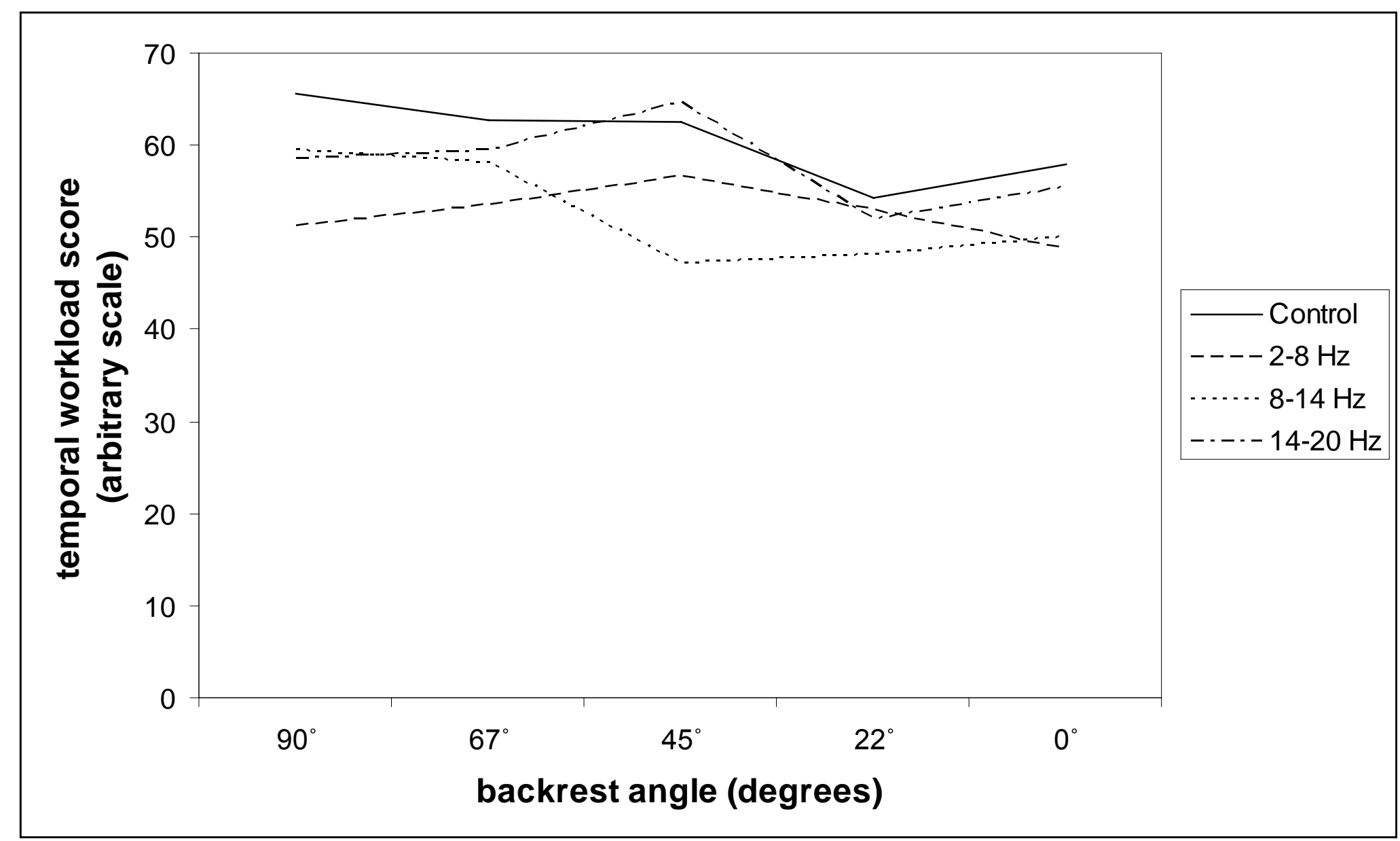

Figure 8 Mean ratings of perceived performance as a function of backrest angle for the three vibration conditions and the control condition, during the tracking task (' 0 supine', ' $90^{\circ}$ upright'). 


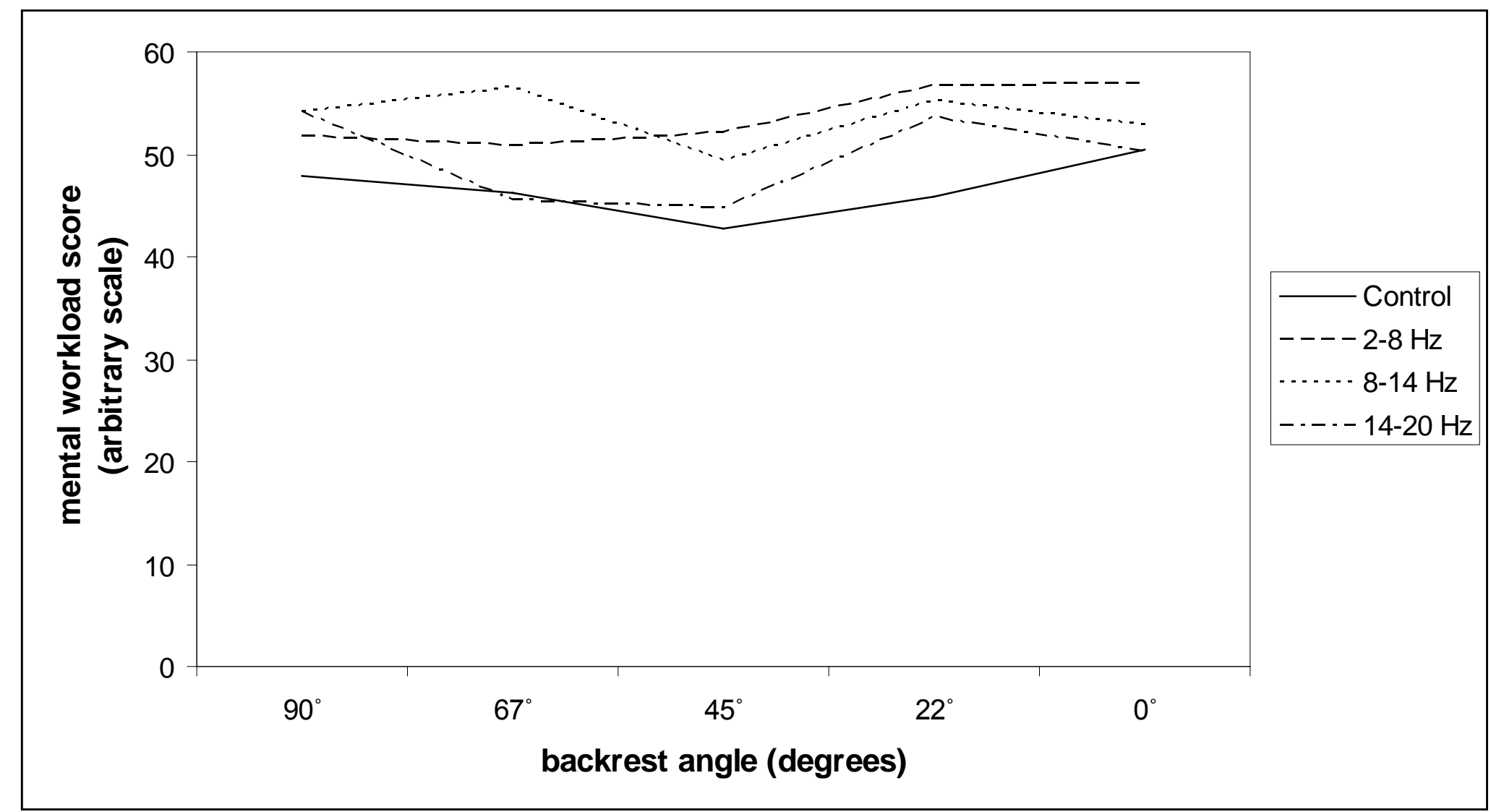

Figure 9 Mean perceived mental workload as a function of backrest angle for the three vibration conditions and the control condition, during the tracking task ('0 $0^{\circ}$ supine', ' $90^{\circ}$ upright'). 


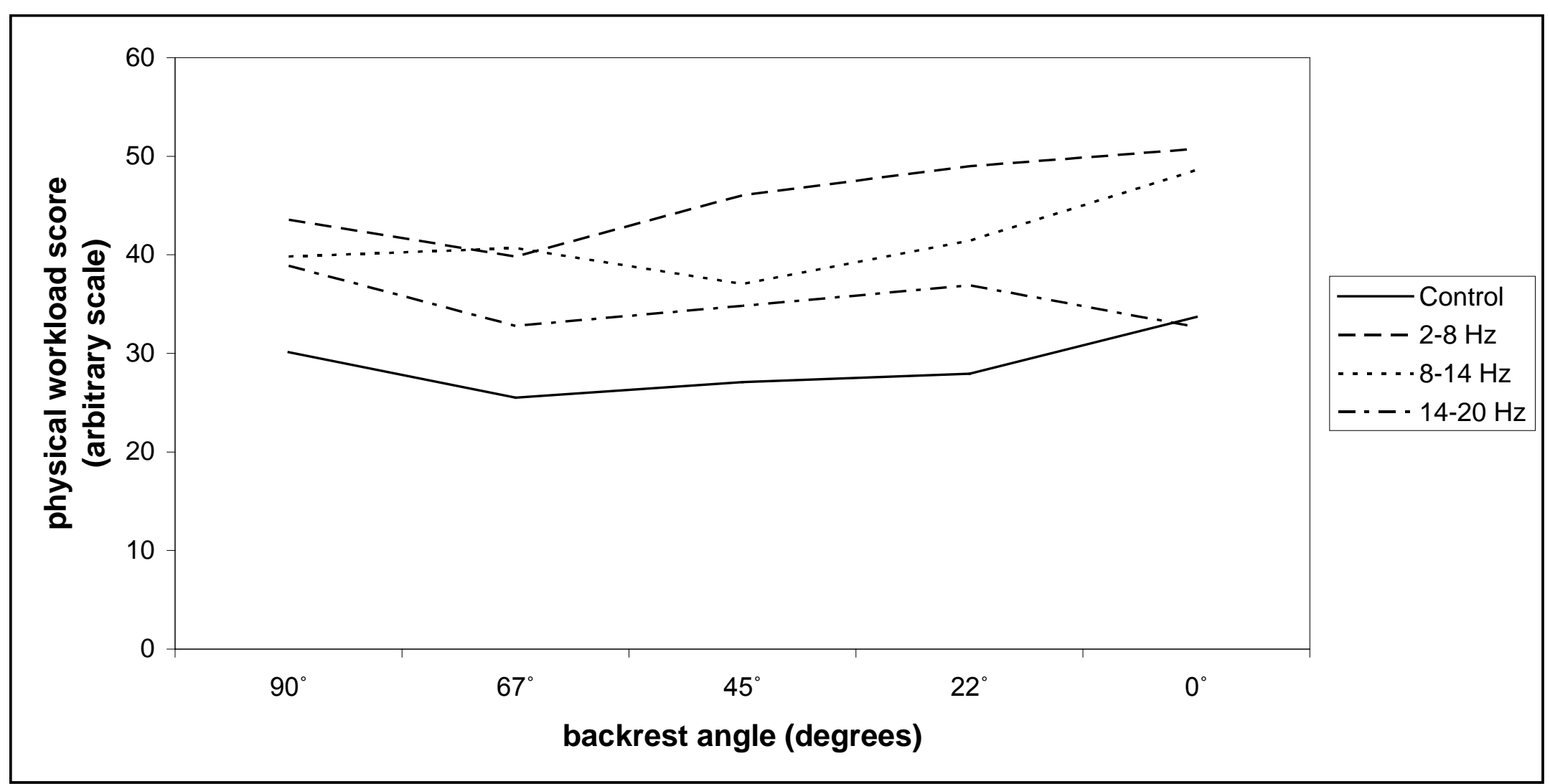

Figure 10 Mean perceived physical workload as a function of backrest angle for the three vibration conditions and the control condition, during the choice reaction time task (' 0 supine', ' $90^{\circ}$ upright'). 


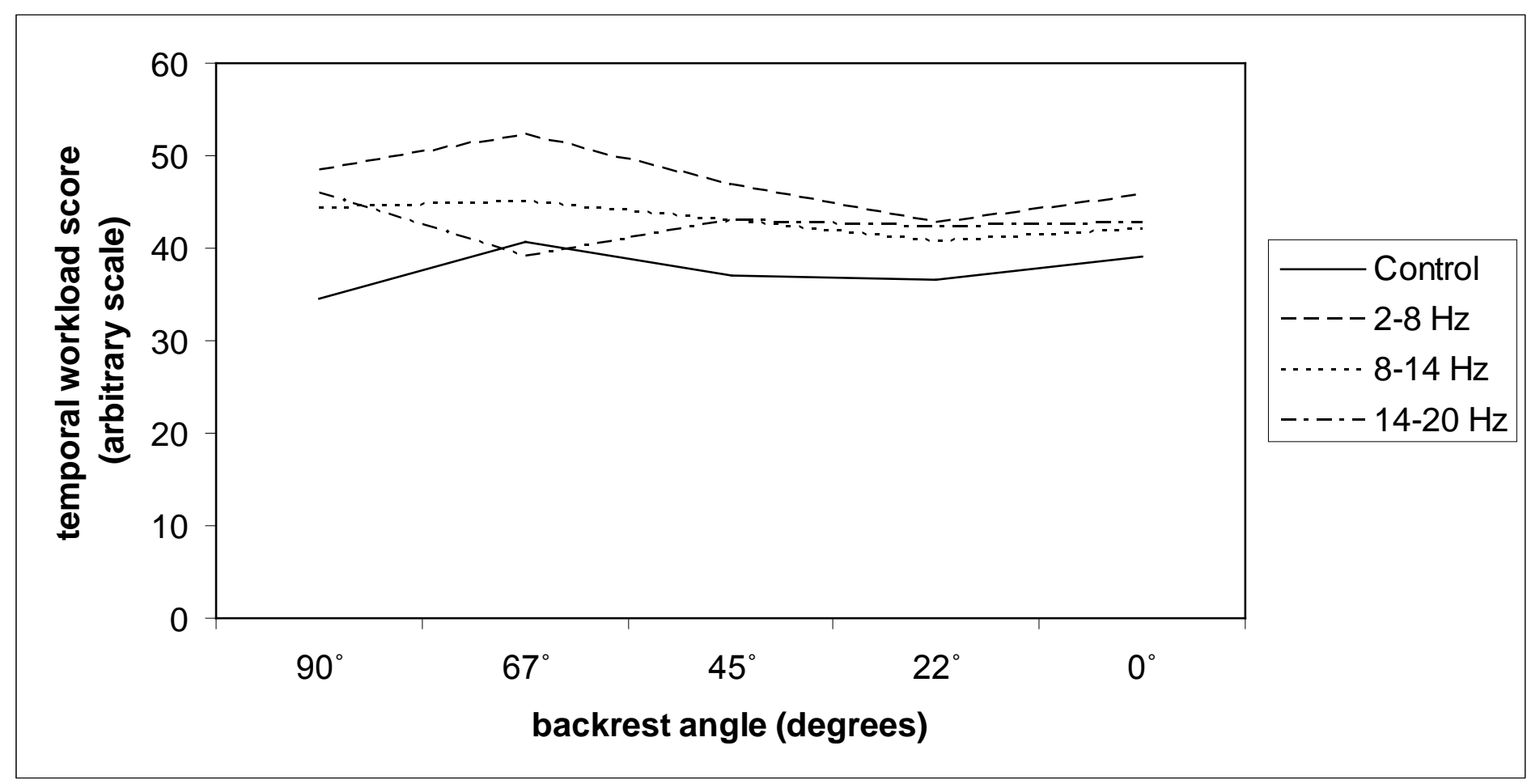

Figure 11 Mean perceived temporal workload as a function of backrest angle for the three vibration conditions and the control condition, during the choice reaction time task (' 0 supine', ' $90^{\circ}$ upright'). 


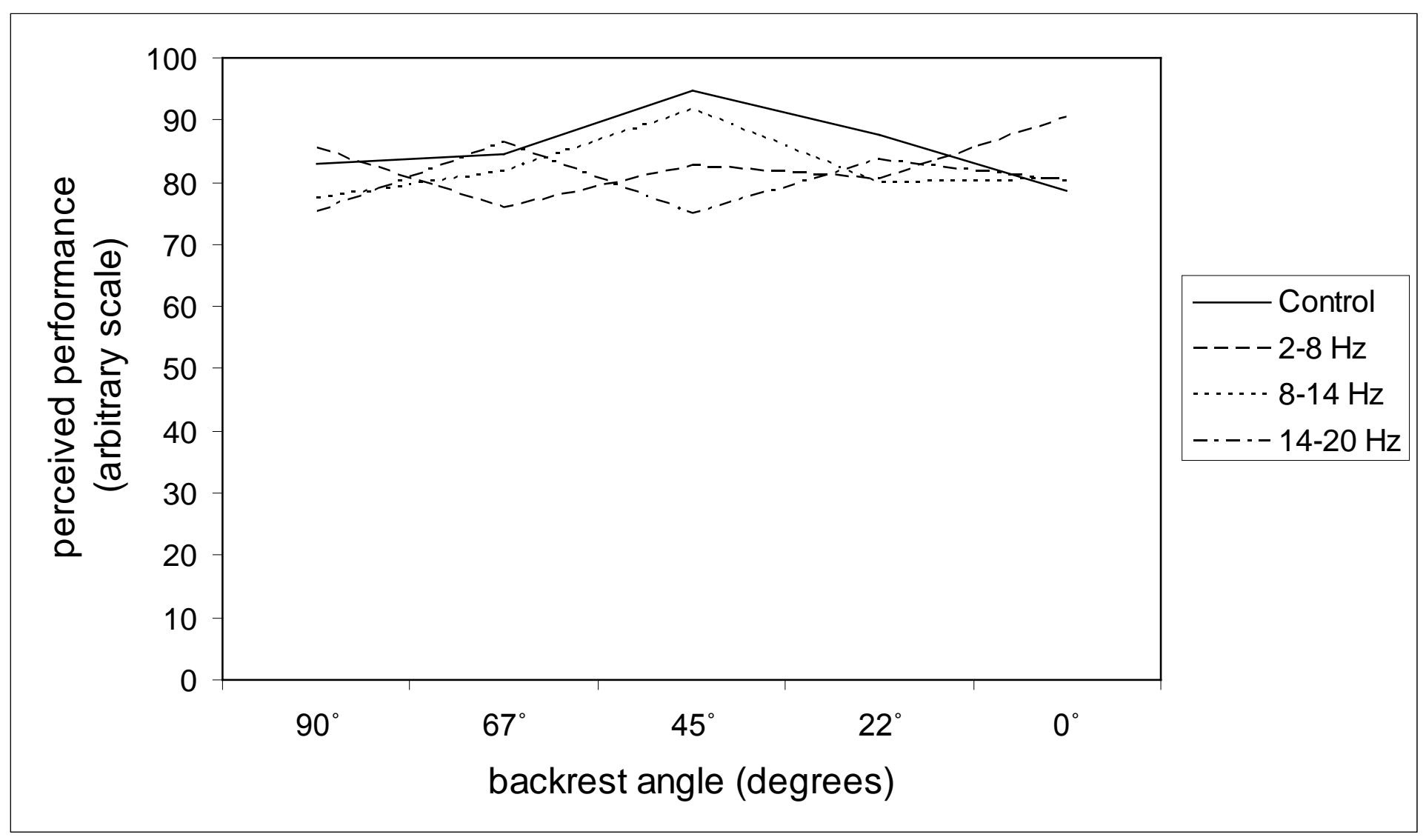

Figure 12 Mean perceived performance ratings as a function of backrest angle for the three vibration conditions and the control condition, during the choice reaction time task (' $0{ }^{\circ}$ supine', ' $90^{\circ}$ upright'). 


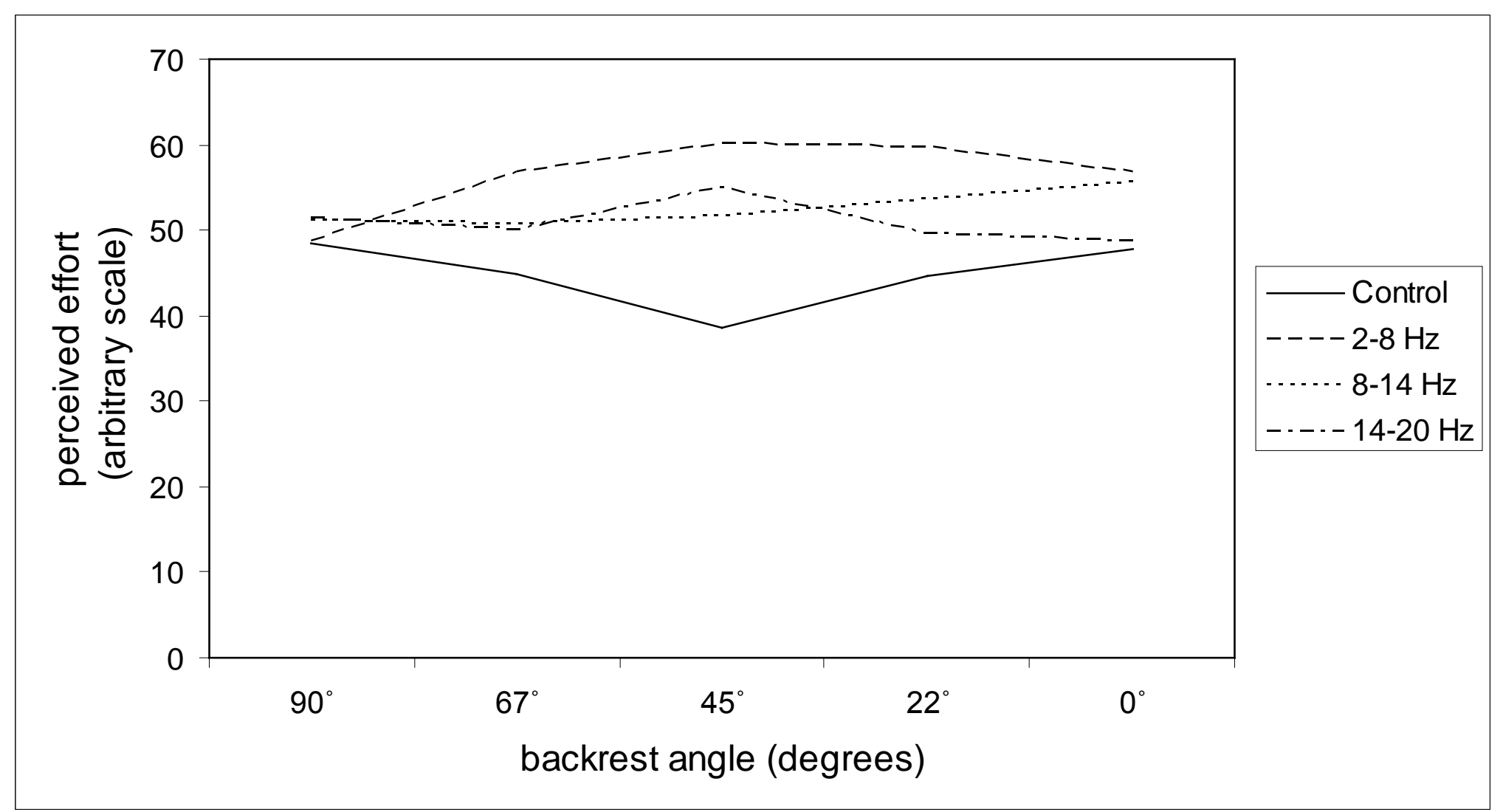

Figure 13 Mean perceived effort as a function of backrest angle for the three vibration conditions and the control condition, during the choice reaction time task (' $0{ }^{\circ}$ supine', ' $90^{\circ}$ upright'). 